\title{
The management of thyrotoxicosis in a pre-pubertal child with $18 p$ deletion syndrome
}

\author{
P Dharmaraj and A Grueters ${ }^{1}$ \\ Department of Paediatric Endocrinology, Royal Victoria Infirmary, Newcastle-upon-Tyne, UK and ${ }^{1}$ Zentrum fur Kinder und Jungendmedizin der Humbolt \\ Universitat, Berlin, Germany
}

(Correspondence should be addressed to P Dharmaraj; Email: poonamd@doctors.org.uk)

\begin{abstract}
A female baby, born at term weighing $3.2 \mathrm{~kg}$ was noted to have bilateral ptosis and epicanthic folds. Karyotyping during infancy revealed a terminal deletion of the short arm of chromosome 18, which is known to be associated with pituitary hormone deficiency, learning difficulties, restlessness and emotional lability. At the age of 5, she was growing slowly and pituitary function testing showed satisfactory GH and cortisol responses, but TSH was below the assay threshold and free thyroxine and tri-iodothyronine were elevated. Thyrotoxicosis was confirmed and she was treated with carbimazole, which she failed to respond to, even at high doses. The drug was stopped when she became neutropenic and was rendered euthyroid with sodium iopodate prior to surgery. Total thyroidectomy was performed successfully and she has subsequently shown improvement in her cognitive symptoms and general development.
\end{abstract}

European Journal of Endocrinology 155 S145-S147

\section{Introduction}

The most common cause of thyrotoxicosis in childhood is juvenile Graves' disease, with an incidence of 0.1 per 100000 in young children, rising to 3 per 100000 in adolescence (1). Children make up only $5-6 \%$ of the total population with thyrotoxicosis, but those with chromosomal abnormalities have an increased incidence of this condition as well as other autoimmune diseases. It is not uncommon for symptoms to have been present for many months prior to diagnosis, particularly in the pre-pubertal child (2). Thus, the diagnosis of thyrotoxicosis in children is often delayed. Treatment of childhood thyrotoxicosis remains challenging and may require multidisciplinary management. The three treatment modalities - anti-thyroid drugs (ATDs), radioactive iodine (I-131) and surgery - each have their risks and benefits, particularly in the very young patient. Parents often face a dilemma rather than a choice, and may base treatment decisions on factors that the clinician has not considered.

We describe our experience of treating Graves' disease in a child with $18 \mathrm{p}$ deletion syndrome, and highlight the controversies which still surround the management of this condition.

This paper was presented at the 4th Ferring Pharmaceuticals International Paediatric Endocrinology Symposium, Paris (2006). Ferring Pharmaceuticals has supported the publication of these proceedings.

\section{Case report}

Our patient was born following a full-term normal delivery, with a weight of $3.2 \mathrm{~kg}$. She was noted to have bilateral ptosis and epicanthic folds soon after birth, and during infancy she developed drooling and expressive dysphasia. Karyotyping demonstrated a terminal deletion of the short arm of chromosome 18 (46,XX,del(18)(p11.1)), which was a de novo rearrangement (18p deletion syndrome shows broad variability in its phenotype but consistent features include mental and growth deficiencies and ptosis, epicanthic folds and prominent auricles. Mean parental ages tend to be older than average). She was referred to the growth clinic at 5 years of age because of concerns about short stature, her height SDS being -3 s.D. below the mean. She also had periods of difficult behaviour with emotional lability, restlessness and speech and language delay. As there is a recognised association between 18p deletion syndrome and pituitary hormone deficiency, appropriate investigations were undertaken.

Cranial magnetic resonance imaging scan showed an underdeveloped pituitary gland with a high posterior pituitary bright spot. Provocation testing using glucagon and Thyrotrophin-releasing hormone (TRH) demonstrated adequate responses to both growth hormone (GH) and cortisol, but thyroid-stimulating hormone (TSH) values were below the assay threshold and both free thyroxine $\left(\mathrm{fT}_{4}\right)$ and tri-iodothyronine $\left(\mathrm{fT}_{3}\right)$ were elevated at $26 \mathrm{pmol} / \mathrm{l}$ (reference range $11-23 \mathrm{pmol} / \mathrm{l}$ ) 
and $13.6 \mathrm{pmol} / \mathrm{l}$ (reference range $3.5-5.2 \mathrm{pmol} / \mathrm{l}$ ) respectively. Thyroid peroxidase antibodies were strongly positive and TSH receptor-binding inhibitory immunoglobulin (TBII) elevated at 55\% (normal range 0-10\%). She was noted to have a small goitre clinically and a resting tachycardia.

Carbimazole was commenced at $1 \mathrm{mg} / \mathrm{kg}$ per day, but she remained biochemically thyrotoxic both at this dose and a higher dose of $1.6 \mathrm{mg} / \mathrm{kg}$ per day. Nine months after starting treatment, a routine blood count revealed a neutrophil count of $0.86 \times 10^{9} / 1$ and the drug was discontinued. Despite the use of $\beta$-blockade, she demonstrated clinical and biochemical thyroid hormone excess (Fig. 1).

At this point, the options of radioiodine or surgery were explored with the parents, and total thyroidectomy was their treatment of choice. The main factor governing this was that it would be difficult and detrimental for their child to be separated from her siblings in the immediate post-treatment period following radioiodine. As she was presently thyrotoxic and unable to tolerate ATD's, the patient was treated with sodium iopodate (an iodinated oral radiographic contrast agent) at a dose of $500 \mathrm{mg}$ daily for 10 days, at the end of which she was biochemically euthyroid for the first time in 12 months.

She then underwent a total thyroidectomy, which was complicated by post-operative hypocalcaemia requiring calcium supplementation for 3 months. She is presently maintained on thyroxine replacement and, although she remains short, there has been noticeable improvement in her speech, communication and behavioural symptoms.

\section{Discussion}

The 18p deletion syndrome was first described in 1963 by de Grouchy et al. (3) and more than 100 cases have been reported worldwide. The phenotype is variable but consistent features include growth failure, learning difficulties, restlessness, poor concentration and

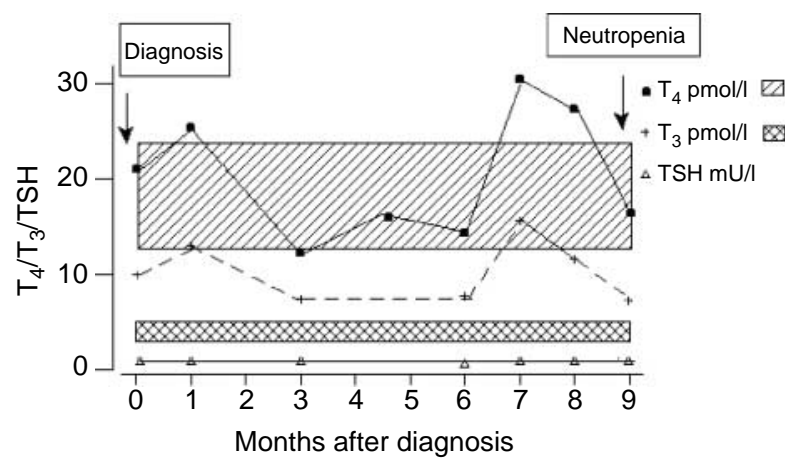

Figure 1 From diagnosis to neutropenia: 9 months of thyrotoxicosis despite carbimazole treatment. $\mathrm{T}_{4}$, thyroxine; $\mathrm{T}_{3}$, tri-iodothyronine; $\mathrm{TSH}$, thyroid-stimulating hormone. emotional lability. There is an association with autoimmune disease, including type 1 diabetes, thyroiditis and Graves' disease. Pituitary hormone deficiency has also been described in these patients.

Graves' disease in the pre-pubertal age group tends to present atypically, runs a more severe course and requires a longer time to remit (4). For these reasons, it presents a challenge in management. Accelerated growth and advanced bone age are common features in the very young child $(5,6)$, so it is interesting that our patient was actually being investigated for short stature and that Graves' disease was identified 'accidentally'.

It could be argued that the most probable reason for failure to respond to ATDs is non-compliance, but we also know that pre-pubertal children with Graves' disease have more adverse reactions to ATDs $(5,7)$ and an overall lower remission rate $(<30 \%)$ with medical therapy (4). The mechanism of drug-induced agranulocytosis is immune-mediated destruction of neutrophils and usually occurs within the first 3 months of treatment (8). Side effects such as neutropenia may be more common in patients on larger doses of ATD and this is a possibility in our case. Certainly, the fact that younger patients may be more sensitive to ATDs has been recognised by other groups (6). We elected not to switch to another ATD, namely propylthiouracil (PTU), following the publication of data from the UK Committee on Safety of Medicines, which showed more reports of adverse drug reactions, including neutropenia, per prescription of PTU than carbimazole, over a 22-year period (8).

There is a longstanding debate about the management of patients who relapse and do not want to return to ATD treatment, who cannot tolerate ATDs or who are poorly compliant. In an ideal world, a family should receive all the information necessary from the relevant parties in order to make an informed choice, which is personal to their situation. In reality, decisions are often dictated by the proximity and expertise of a paediatric thyroid surgeon, and the experience of a department in using radioiodine treatment in children. In the past, reluctance to use I-131 in young patients was linked to long-term safety concerns but follow-up studies of cancer risk (thyroid and extra-thyroid) in patients treated with radioiodine have largely been reassuring (9).

Read et al. (10) reported 26- and 36-year outcomes of 116 patients who were treated with radioiodine under the age of 20. None developed thyroid cancer or leukaemia and all but two eventually achieved hypothyroidism. It was also reported that the miscarriage and congenital abnormality rate in the next generation was not increased. In fact, it has been shown that the incidence of thyroid malignancy over a 10-20 year follow-up period is five times greater in adult patients treated with ATDs than in those given radioiodine, and eight times greater than in those who undergo surgery (11). This reflects the persistence of thyroid tissue as a potential site of neoplastic change, rather than suggesting a causative role for ATDs. 
Rivkees et al. have shown that higher doses of I-131 (at least $270 \mathrm{~Gy}$ ) are required to ensure ablation of the gland and achieve hypothyroidism, thereby reducing the risk of developing malignancy in non-ablated tissue, as well as avoiding the need for a second dose of treatment (12). Safety concerns linger in the very young, particularly those under 5 years of age. It is a fact that children have a greater total body radiation exposure per $\mathrm{mCi}$ than adults, giving them a theoretically higher risk of nonthyroidal cancer in the long-term. The follow-up of all young people who have received radioiodine therapy is vital, so that we can be more certain about the risks and benefits, particularly in the pre-pubertal group.

In our case, the parents were concerned about the detrimental effect of separating the patient from her siblings for at least 2 weeks following radioiodine treatment. It should be remembered that children with learning difficulties have special needs which may lead to surprising choices. Our patient's thyrotoxicosis was only successfully controlled 12 months after diagnosis - this is not atypical of pre-pubertal Graves' disease and is why Lazar et al. have suggested the earlier consideration of definitive treatment in this group (6). The improvement in her cognitive symptoms postoperatively indicates that they were due, at least in part, to the underlying thyroid problem, illustrating just how difficult it can be to accurately pin-point symptoms of thyrotoxicosis in this age group, particularly in a child with learning difficulties. Sixty years after the introduction of ATDs, we are no better off in terms of our treatment choices for autoimmune thyroid disease, but we are armed with more information than ever before. It is vital that we use our knowledge wisely, to guide families towards the safest, and yet most effective treatment available.

\section{Key learning points}

- The management of pre-pubertal Graves' disease is challenging and may necessitate the early consideration of definitive treatment.

- Younger patients tend to show a higher rate of side effects of ATDs.

- Atypical or confusing clinical symptoms may result in delayed or incidental diagnosis of thyrotoxicosis.

- Children with learning difficulties have special needs which may influence treatment choices by their parents.

\section{References}

1 Lavard L, Ranlov R, Perrild H, Anderson A \& Jacobsen BB. Incidence of juvenile thyrotoxicosis in Denmark, 1982-1988. A natiowide study. European Journal of Endocrinology 1994130 $565-568$.

2 Shulman DI, Muhar I, Jorgensen EV, Diamond FB, Bercu BB \& Root AW. Autoimmmune hyperthyroidism in prepubertal children and adolescents: comparison of clinical and biochemical features at diagnosis and response to medical therapy. Thyroid $1997 \mathbf{7}$ 755-760.

3 de Grouchy J. Dysmorphie complexe avec oligophrenie: Deletion des bras courts d'un chromosome 17-18. D.R. Acad. Sci. [D] (paris) 19632561028

4 Glaser N \& Styne D. Predictors of early remission of hyperthyroidism in children. Journal of Clinical Endocrinology and Metabolism 199782 1719-1726.

5 Zimmerman D \& Lteif AN. Thyrotoxicosis in children. Endocrinology and Metabolism Clinics of North America 19987 109-125.

6 Lazar L, Kalter-Leibovici O, Pertzelan A, Weintrob N, Josefsberg Z \& Phillip M. Thyrotoxicosis in prepubertal children compared with pubertal and postpubertal patients. Journal of Clinical Endocrinology and Metabolism 200085 3678-3682.

7 Hamburger JI. Management of hyperthyroidism in children and adolescents. Journal of Clinical Endocrinology and Metabolism 1985 60 1019-1024.

8 Pearce SHS. Spontaneous reporting of adverse reactions to carbimazole and propylthiouracil in the United Kingdom. Clinical Endocrinology 200461 589-594.

9 Ron E, Doody MM, Becker DV, Brill AB, Curtis RE, Goldman MB, Harris BS, III, Hoffman DA, McConahey WM, Maxon HR, PrestonMartin S, Warshauer ME, Wong FL \& Boice JD Jr. Cancer mortality following treatment for adult hyperthyroidism. Cooperative thyrotoxicosis therapy follow-up study group. JAMA $1998 \mathbf{2 8 0}$ 347-355.

10 Read CH, Tansey MJ \& Menda Y. A 36-year retrospective analysis of the efficacy and safety of radioactive iodine in treating young Graves' patients. Journal of Clinical Endocrinology and Metabolism 200489 4229-4233.

11 Dobyns BM, Sheline GE, Workman JB, Tompkins EA, McConahey WM \& Becker DV. Malignant and benign neoplasms of the thyroid in patients treated for hyperthyroidism: a report of the cooperative thyrotoxicosis therapy follow-up study. Journal of Clinical Endocrinology and Metabolism 197438 976-998.

12 Rivkees SA \& Cornelius EA. Influence of iodine-131 dose on the outcome of hyperthyroidism in children. Pediatrics $2003 \mathbf{1 1 1}$ 745-749.

Received 14 July 2006

Accepted 22 August 2006 